\section{Hacia una sociedad aséptica. Modos de vida y politicidades pandémicas}

Towards an aseptic society. Livelihoods and pandemic politicities

\author{
Mariana Betzabeth Pelayo Pérez
}

\section{RESUMEN}

La pandemia provocada por COVID-19 se inscribió en nuestros cuerpos y en nuestros sentidos. Habitar la pandemia representó la reconfiguración de nuestros tiempos, ritmos, procesos de subjetivación, socialización y productividad, formas de concebir el mundo, así como los ciclos de la vida y los rituales de la muerte. Aunque este acontecimiento se debe en gran parte a factores biológicos y epidemiológicos, también se ha constituido como un operador que ha producido discursos, prácticas, imaginarios y deseos, donde el poder fluye y maquina nuevos reordenamientos a la luz de la entropía, el terror social y el riesgo pandémico. En este artículo se tuvo como objetivo analizar los nuevos condicionamientos materiales e inmateriales que se reconfiguraron en la sociedad civil durante el marco temporal pandémico como mecanismos de afrontamiento y resistencia orientados al resguardo de la vida en la condición de emergencia sanitaria. En la dimensión material se profundiza en las formas en cómo nos reconstituimos como sujetos, la relación y organización de los cuerpos con el hábitat, y la emergencia de nuevas relaciones mercantiles. En la dimensión inmaterial se analizan los aspectos discursivos como las prácticas discriminatorias, la generación de nuevos afectos y la producción de subjetividades. Tales gestos y politicidades están orientados a la continuidad de la sostenibilidad de la vida, sin embargo, desocultan contradicciones, deficiencias, procesos discriminatorios y diversos tipos de violencia que confeccionan una nueva sociedad aséptica.

Palabras clave: Pandemia; Cuerpos; Hábitat; Poder; Políticas de vida

\section{ABSTRACT}

The pandemic caused by COVID-19 was inscribed in our bodies and in our senses. The pandemic represented the reconfiguration of our times, rhythms, processes of subjectivation, socialization, and productivity, even the ways of conceiving the world as the cycles of life and the rituals of death. Although this event is due to biological and epidemiological factors, it has also been established as an operator that has produced discourses, practices, imaginations, and desires, where power flows and organizes new rearrangements in the condition of entropy, social terror, and the pandemic risk. The objective of this article was to analyze the new material and immaterial conditions that were reconfigured in civil society during the pandemic period as coping and resistance mechanisms aimed at safeguarding life in the health emergency condition. The first one delves into the ways in which we reconstitute ourselves as subjects, the relationship and organization of bodies with the habitat, and the emergence of new commercial relationships. In the immaterial dimension, discursive aspects such as discriminatory practices, the generation of new affects and the production of subjectivities are analyzed, such gestures and politicities are oriented to the continuity of the sustainability of life, however, they reveal contradictions, deficiencies, discriminatory processes and distinct types of violence that make up a new aseptic society.

Keywords: Pandemic; Bodies; Habitat; Power; Life policies
RELIGACIÓN

REVISTA DE CIENCIAS SOCIALES Y HUMANIDADES JOURNAL OF SOCIAL SCIENCES AND HUMANITIES
REVISTA DE CENCIAS SOCIAIS E HUMANAS

INFORMACIÓN:

http://doi.org/10.46652/rgn.v6i30.860 ISSN $2477-9083$

Vol. 6 No. 30, 2021. e210860 Quito, Ecuador

Enviado: octubre 04, 2021

Aceptado: noviembre 28, 2021

Publicado: diciembre 16, 2021

Publicación Continua

Sección Dossier | Peer Reviewed

\section{AUTORES:}

(D) Mariana Betzabeth Pelayo Pérez Universidad Autónoma de Nayarit México

mariana.pelayo@uan.edu.mx

Conflicto de intereses

La autora declara que no existe conflicto de interés posible.

Financiamiento

No existió asistencia financiera de partes externas al presente artículo.

Agradecimiento

$\mathrm{N} / \mathrm{A}$

Nota

El artículo no se desprende de un trabajo anterior.

ENTIDAD EDITORA 


\section{INTRODUCCIÓN}

La pandemia de COVID-19 se inscribió en nuestros cuerpos y en nuestros sentidos. Lo que se percibía como un evento lejano, se volvió un fenómeno de largo aliento que a casi dos años de su aparición ha reconfigurado material y simbólicamente nuestra vidas, ha implicado la modificación de nuestros tiempos, ritmos, procesos de subjetivación, socialización, productividad, formas de concebir el mundo, así como los ciclos de la vida y los rituales de la muerte. El COVID-19 se ha constituido como un operador que ha producido discursos, prácticas, imaginarios y deseos. Un contexto donde el poder fluye y maquina nuevos reordenamientos a la luz de la entropía y el riesgo pandémico.

Tal coyuntura ha instalado prácticas inéditas como la sanitización cotidiana, la aplicación de vacunas y la emergencia de nuevos mercados sanitarios que han modelado determinados hábitos prácticas y estilos de vida, generando consigo comportamientos y formas de politicidad orientadas a la salvaguarda de la salud de la ciudadanía. Sin embargo, esta condición material también se incorporó simbólicamente en nuestros procesos de subjetivación trastocando dimensiones existenciales que visibilizaron contradicciones, deficiencias, procesos discriminatorios y diversos tipos de violencia que han confeccionado una nueva sociedad con rasgos asépticos, propensa al debilitamiento del tejido social y la transformación de las formas de relacionarnos.

El propósito de este estudio es analizar los nuevos condicionamientos materiales e inmateriales que se reconfiguraron en la sociedad civil durante el marco temporal pandémico que se activaron como mecanismos de afrontamiento y resistencia orientados al resguardo de la vida, ante la condición de emergencia sanitaria. Sin embargo, esta condición también generó esquemas de subordinación, dominación, control mediante el despliegue de un poder ubicuo que reordenó sistemática y micropolíticamente a la sociedad, bajo la primicia del resguardo y la seguridad global frente a la pandemia por COVID-19.

Se exploraron, las prácticas, los imaginarios y los deseos emergentes, así como, las formas en que el poder fluye y maquina nuevos reordenamientos a la luz de la entropía y el riesgo a la salud pandémica. En la dimensión material se realizó un bosquejo de las formas en cómo nos reconstituimos como sujetos, la relación y organización de los cuerpos con el hábitat y la emergencia de nuevas relaciones mercantiles. En la dimensión inmaterial se analizaron los aspectos discursivos, las prácticas discriminatorias, la generación de nuevos afectos y la producción de subjetividades.

Los datos obtenidos abonaron a la discusión teórica conceptual y dieron referencia para construir las categorías de análisis desde una reflexión crítica y situada derivada de la documentación, la observación y la experiencia de la autora. Tal proceso permitió conformar un acuerpamiento teórico preliminar y el robustecimiento de las categorías de los modos de vida y las formas de politicidad, que han permitido profundizar en la forma en cómo se han instalado ciertos condicionamientos en los tiempos pandémicos.

La incidencia de este proyecto está orientada en favorecer la comprensión del alcance espaciotemporal, corpóreo y existencial de lo que representó la pandemia. Lo cual permitirá implementar rutas de acción para el tratamiento de las secuelas materiales e inmateriales por COVID-19. Principalmente se busca resaltar los impactos perjudiciales en las dimensión psicosocial, política 
y ambiental. Se espera que estos encuentros posibiliten el transito a un escenario de justicia y ecología social, con la activación de prácticas ciudadanas sostenibles como mecanismos de mitigación sobre los efectos pandémicos que permitan el mantenimiento de la vida y la cohesión social. Este artículo está conformado por tres segmentos; en el primer apartado y como parte de la introducción se despliegan las coordenadas conceptuales y metodológicas que soportan el análisis del presente estudio, en el segundo apartado se presenta el desarrollo donde se desplegó la discusión y los resultados, finalmente en el tercer apartado se puntualizan las conclusiones.

\subsection{Ecología política y geografía de la salud}

Este trabajo se desarrolló desde una perspectiva transdisciplinar desde un enfoque ontológico de la ecología política de la salud y geografía de la salud, coordenadas teórico conceptuales que han permitido ampliar el acervo y el alcance de análisis de los acontecimientos y las condiciones que la pandemia ha ocasionado como un problema de orden socioambiental, político y psicosocial.

Para Harper (2004) la ecología política es una aproximación interdisciplinar del estudio de las relaciones humano-ambiente, que se apoya en estudios empíricos y teóricos de la geografía, sociología, economía, historia, ciencia política y antropología. Los ecólogos políticos tienden a observar el impacto social y ambiental y las fuerzas sociales que lo configuran. La ecología política combina los niveles de análisis desde lo individual, familiar, comunidad, estado-nación y la economía internacional. Estos vínculos combinados reconocen que los sistemas ecológicos y sociales interactúan de manera desigual a lo largo del tiempo y espacio, lo cual conduce a concluir que las relaciones entre los seres humanos y el medio ambiente deben contextualizar a nivel local para facilitar la compleja discusión de la forma en que los humanos interactúan con el medio ambiente.

Según Leff (2014) la ecología política es un campo de conflicto y un laboratorio de experiencias de emancipación nutrido por una ética política que renueva el sentido y las condiciones de sustentabilidad de la vida, volviéndose un campo de encuentro, confrontación y convivencia entre los diferentes modos de construir la vida humana en el planeta. A partir de lo anterior, para este trabajo la ecología política es un campo de enfoques orientados al estudio material y sensible de los sistemas de vida, cuyo propósito es comprender la interrelación de lo humano y lo no humano y la trascendencia de esta correspondencia en la configuración de metabolismos, ecosistemas y órdenes socioambientales para preservar los sistemas de vida.

Esta interrelación coloca como prioridad el análisis de cómo los entornos tienen agencia en los cuerpos y factores psicosociales de los individuos. Esta variación en el campo de la ecología política alude a la ecología política posthumanista, la cual se concentra en la dimensión ontológica de las relaciones sociedad-naturaleza donde se analizan las prácticas en los múltiples vínculos entre actores humanos y no humanos, así como, en su capacidad de actuar, afectar y ser afectados y constituirse así en sujetos políticos dentro de los escenarios socioambientales (Hobson, 2007; Sundberg, 2011).

Dicho enfoque permite considerar a los actores con la capacidad de influir y movilizar procesos, consiste en ir más allá de la brecha entre naturaleza y cultura. Al difuminar la brecha ontológica naturaleza-cultura, se establece una ontología relacional (Haraway, 2003) que permite visibilizar la capacidad de agencia de los seres no humanos en distintas esferas y procesos, como 
mutuamente constituidas en y a través de las relaciones sociales (Castree, 2003; Hobson, 2007), este aparato analítico es de vital importancia cuando se desea construir una ecología política de la salud y analizar el marco temporal de la pandemia por COVID-19.

Algunos estudios referentes a la ecología política de la salud como el realizado por Coburn (2000)y Geronimus (2000) analizan los modelos de desigualdad asociados a factores macroeconómicos, estructurales y racistas para comprender los patrones desiguales de salud y enfermedad. Ante esto, los ecologistas políticos reconocen las disparidades sociales vinculadas con la salud desigual y han empleado un enfoque para comprender cómo los impactos del cambio ambiental afectan en los seres vivos y la salud humana.

No obstante, Harper (2004) propone que se complejicen los análisis desde la relación entre salud y medio ambiente, reconociendo que las desigualdades estructurales contribuyen en un mayor riesgo de enfermedad, poco o ningún acceso a un tratamiento eficaz, entornos insalubres y trayectorias de salud deficientes para determinados grupos sociales. El autor, asevera que la enfermedad no se puede ver como un estado biomédico sino como un problema de salud modelado por relaciones sociales y las desigualdades como la desnutrición, peligros ambientales, viviendas precarias y pobreza, donde los entornos y el medio ambiente afectan a las poblaciones. Sin embargo, es necesario, tomar en cuenta la violencia estructural que perpetúa las desigualdades, de esta forma la desigualdad social y el poder son factores elementales en el estado de salud (Baer et al., 1997).

Un ejemplo es el trabajo de Ennis-McMillan (2001) quien ha demostrado en su estudio sobre la percepción de la población mexicana o el "Sufrimiento de agua" cómo los problemas de salud ambiental fueron derivados por los conflictos hídricos de distribución y uso de recursos. En este tipo de casos la ecología política de la salud puede ser una herramienta analítica útil en la comprensión de cómo las relaciones sociales, el cuerpo y el medio ambiente adquieren significado y para conceptualizar la desigualdad social, problemas de salud, contaminación y despojos.

El medio ambiente aquí alude al espacio o entorno repositorio de toda actividad humana que se habita, vive y encarna. El ambiente es un determinante en la condición bioquímica y psicosocial de los individuos y en los estados de salud colectiva. Las exposiciones ambientales, implican una transmisión bioquímica entre aire, agua, suelo, comida y el cuerpo. La ecología política de la salud se enfoca en cómo las acciones humanas, y especialmente a los procesos políticos económicos, cambio ecológico a gran escala dan formas a nuevos problemas de salud (Gabrielson y Parady, 2010).

El enfoque en la ecología política de la salud se ha centrado principalmente en la degradación del medio ambiente, contando una historia de la salud humana como efecto de la intromisión humana en el medio ambiente (Gabrielson y Parady, 2010). Brown (2006) propone explorar las intersecciones entre ecología política y las experiencias encarnadas de vivir con una enfermedad exploradas en el trabajo de la salud. El autor se basó en la ecología política como un medio para cuestionar los imaginarios sociales dominantes de las personas que viven con SIDA, lo que sugiere que debemos profundizar en el reconocimiento de las personas y las ecologías cotidianas de las relaciones humano-virus.

Para ello es necesario experimentar el entorno, cómo cohabitamos y cómo “devenimos con" (Haraway, 2008), esto implica la activación y sensibilización de un saber ambiental emergente 
(Leff, 1998) que posibilita nuevas formas de coevolucionar y cohabitar entre especies. Para Greenhough (2012), los espacios de las relaciones humano-virus son objeto de formas particulares de gobernanza política y económica (geopolítica) refractadas a través de redes, entornos, discursos sociopolíticos y urbanos-industriales (ecología política), también son producidos activamente por las formas en que los humanos aprenden a adaptarse y comunicarse con agencia viral.

Cabe resaltar que el medio ambiente sigue siendo en gran parte un lugar que tiene características específicas que puede dañar y/o promover la salud. El medio ambiente es un cúmulo son activos y procesos que son simultáneamente políticos y biofísicos, por lo tanto, se identifica como un mundo socioambiental. El medio ambiente afecta al cuerpo, pero lo que sucede dentro del cuerpo es algo que la ecología política aún tiene que abordar, conceptual o empíricamente. Ante esto, Gabrielson y Parady (2010) afirman que la experiencia de habitar en diversos entornos sociales y naturales tanto discursivos y materiales da forma a la subjetividad y la condición del lugar como entorno, sin embargo, la noción de entorno trasciende a ser experiencial y relacional, desde un enfoque espacial interactivo.

A partir de lo anterior, es importante integrar un enfoque que puede aportar nociones oportunas a este trabajo, se trata de la geografía de la salud, la cual adopta una visión relacional del espacio (Cummins et al., 2007). Según Guthman y Mansfield (2012) la geografía de la salud se está desarrollando desde la teoría de la complejidad de relaciones, esta comprensión promueve una mayor sensibilidad en investigación en tiempo y espacio para prever tendencias de interacciones menores que evolucionan en partes del sistema como personas, factores de riesgo fisiológico y el tejido físico del entorno sanitario.

La geografía de la salud se enfoca en procesos y relaciones en el espacio y el tiempo que gobiernan interacciones humanas con su entorno entre sí de forma compleja y no lineal, donde debe analizarse el contexto desde una escala más amplia de economía, política, cambios sociales y ambientales. Este enfoque asume que las desigualdades entre poblaciones pueden verse desde un enfoque histórico informado tales como circunstancias sociales asociadas a la enfermedad, brotes o desventajas de salud sostenidas para ciertos grupos de población (Curtis y Riva, 2010). Según Turshen (1977) y Mayer (2000), estos enfoques hacen hincapié en cómo la salud y las enfermedades emergentes son producto de un amplio ensamblaje de factores ecológicos, procesos políticos, sociales y económicos que evolucionan con el tiempo en diversas áreas geográficas.

Se han generado estudios desde este enfoque como el realizado por Hanchette (2008) quién identificó la persistencia de las altas tasas de envenenamiento infantil por plomo en Carolina del Norte, condición que tuvo una correlación con aspectos sociales y económicos. Otro estudio realizado por Boyle et al., (2002) y Cox et al., (2007) advirtieron como el grado de movilidad residencial puede ser importante en diferencias de salud entre áreas donde las personas que muestran buena salud tienen patrones de migración diferentes de las que se encuentran en extrema pobreza. Se agrega el análisis de Emch et al., (2008) quienes investigaron el significado de riesgo del cólera en Bangladesh y la conectividad de los sistemas de agua. Estos ejemplos ilustran la exposición y la sensibilidad a condiciones previas de peligro y riesgo por desigualdades 
geográficas.

Por su parte Braun (2007) asevera que las enfermedades zoonóticas como el SARS superan los límites de la ciudad y los cuerpos desplazando a los cuerpos en una especie de geografías moleculares que se extienden, más allá del entorno inmediato. Tal afirmación es importante para la comprensión topológica de los espacios de la ciudad y los cuerpos que los habitan. Por ello, las geografías de la salud y el riesgo llegan a verse como una madeja de redes cambiantes locales, globales, biológicas y políticas con sus propios espacios y temporalidades.

Braun advierte que el proceso de observar la ciudad a través del lente de las enfermedades infecciosas permite considerar las formas cotidianas en las que el poder penetra los cuerpos mediante la ingeniería, el espacio o la inoculación de hábitos. Así como la forma en que ciertos cuerpos se incluyen dentro de la ciudad biopolítica mediante los mecanismos de exclusión, globalización y biopolítica. No se trata sólo de los espacios internos de la ciudad, sino que cada vez los proyectos globales de bioseguridad comprenden la mutabilidad biológica y la incrustación del tiempo y espacio como problemas y razones políticas. Algunos ejemplos de este novedoso campo de estudio se registran en el estudio realizado por Ali y Keil, (2008) que informa de un brote de E. Coli transmitido por el agua, por un lado, consecuencia de procesos ecológicos como lluvias extremas, granjas industriales y nuevas cepas de E. Coli y por otro por condiciones socioeconómicas que dan lugar a la negligencia de la gestión del agua incluyendo su privatización, debilitamiento del gobierno y las fuerzas del mercado global.

\subsection{Los cuerpos con el hábitat}

El humano tiene la capacidad tecnológica de crear cuerpos cuya composición y función irrumpen el ideal de lo humano, ya no se respetan las fronteras entre lo animal, lo humano y lo tecnológico (Castree y Nash, 2006; Ferrando, 2013). Los seres y sus cuerpos son producto o efecto de su propia composición, de sus potencialidades y de las relaciones con las cuales se engarzan en el mundo (Braun, 2004). Por esta razón, se utilizan diversos conceptos como redes, ensamblajes, actantes, formaciones socionaturales, híbridas y colectivos como herramientas analíticas para concebir los procesos de co-creación entre entidades humanas y no-humanas; en donde lo no humano representa cosas y seres que van de lo material a lo inmaterial y de lo orgánico a lo inorgánico (Rocheleau y Roth, 2007; Braun, 2008; Sundberg, 2011; Durand y Sundberg, 2019).

Gabrielson y Parady (2010) afirman que los cuerpos son porosos, resistentes, plurales y conectados. Los autores proponen que se retome la fisicalidad de los sistemas corporales, resaltando que los cuerpos están inscritos socialmente por diversos marcadores que expresan poderes disciplinarios que construyen significados dominantes del cuerpo y posicionan a los individuos de forma distinta en la política. Desde su propuesta de la ciudadanía corpórea enfatizan en la corporeidad común de los humanos y el mundo natural no humano.

Según los autores este enfoque ontológico concibe la agencia como encarnada y distribuida ampliamente a través de materialidades y ensamblajes, sitúa la agencia dentro de contextos particulares y resalta su carácter colectivo y emergente. También dirige la atención de espacios en los que habitan los cuerpos y los efectos diferenciales del entorno en la constitución de los cuerpos humanos. Se hace evidente el hecho de que no todos los cuerpos humanos están en una posición similar o están igualmente abiertos a los múltiples flujos de materiales que forman las 
redes de la vida (y la muerte). La estratificación de los contextos socionaturales en los que los seres humanos están inmersos revela la exposición desigual de los cuerpos humanos a tóxicos, patógenos, desastres naturales y factores climáticos y otros factores estresantes ambientales.

Ante esto, los cuerpos siempre están en el proceso de formación a través de sus conexiones con otros cuerpos y esto tiene efectos. Según Braun (2007) la genética nos ha dado un cuerpo conocido a escala molecular, pero también nos dio otra forma de concebir nuestra existencia biológica, ya no como cuerpo autónomo cuya herencia genética debe ser manejada y mejorada, sino como un cuerpo incrustado en un caótico e impredecible mundo molecular. Un cuerpo entendido en términos de una economía general de intercambio y circulación, amenazado por el espectro de riesgos emergentes.

Con la experiencia de las enfermedades por zoonosis, la conectividad y relacionalidad pueden afectar positiva o negativamente, las conexiones son necesarias para los cuerpos para persistir. Según Van Loon (2005) estas conexiones son innumerables, las agencias humanas y virales están enredadas junto a una serie de otras entidades humanas y no humanas desde los sistemas de transporte, las políticas estatales y la Organización Mundial de la Salud, generando un espacio epidémico como espacio denso, marcado por conexiones complejas entre una amplia gama de nodos: pacientes, personal médico, equipos, modos de transporte, carreteras, salas de hospital, virulentos patógenos, parásitos, animales, tecnologías de la comunicación, personal militar, armas, alambre de púas, pero también actores menos tangibles como regulaciones, procedimientos y cuentas (Van Loon, 2005). Estas conexiones pueden hacer que los cuerpos sean vulnerables a virus y bacterias, o tecnologías urbanas como las redes eléctricas o las automóviles, todos amenazan con desterritorializar el cuerpo de manera catastrófica.

Por su parte, Greenhough (2012) sugiere poner más atención a la naturaleza específica de las entidades no humanas como los virus y otros agentes patógenos con los que nos relacionamos e involucramos en la cotidianidad para entender las geografías vitales que ellos inscriben. Esto es entender que la agencia viral también juega un papel importante en la configuración de las relaciones humano-virus y en la producción de espacio epidémico o endémico. Haraway (2008), afirma que somos mezclas con nuestras especies compañeras, debemos pensarnos desde este compañerismo entre especies en tanto la dimensión social y molecular, donde se ejecutan intercambios moleculares y virales entre especies que permiten cierto nivel de coevolución.

Para Braun (2007) las actuales condiciones endémicas y la existencia de los avances en biotecnología resalta la preocupación del futuro posthumano de la sociedad. El autor alude que la existencia de historias de aves migratorias, patios traseros con pollos de los campesinos vietnamitas, el virus de influenza y la seguridad nacional compaginan dos vertientes para el análisis; desde la biopolítica y geopolítica del cuerpo, la molecularidad y la bioseguridad. Esta situación merece atención debido a que las formas de ejercer racionalidades políticas ya no se ubican sólo en la gubernamentalización de la vida, sino en el alcance del poder soberano donde la vida es cada vez más integrada a la ley.

En resumen, las mismas conexiones que habilitan o aumentan la vitalidad de los cuerpos también exponen el cuerpo a fuerzas que amenazan su composición, ante esto los cuerpos, el entorno y los virus han demostrado que son un entramado de redes que mezclan marcadores políticos, químicos, biológicos y tecnológicos. Este entramado debería ser observado desde una 
ontología relacional humano-naturaleza, como un sistema dinámico en donde nuestros cuerpos intercambian propiedades continuamente con virus, insectos, bacterias y otras entidades no humanas que se conectan. Ante ello, se propone entender el cuerpo como un conjunto de relaciones y movimientos con animales y alimentos, que está ubicado en un conjunto de sistemas extracorpóreos como el aire, agua, el clima y gérmenes.

Un ejemplo de ello se ubica en el estudio de Sze (2006) quién analiza la distribución del estrógeno artificial dietilestilbestrol (DES) a través del marco de "cuerpos tecnológicamente contaminados" el cual inicialmente fue distribuido para engordar vacas y pollos para el consumo y prevenir abortos espontáneos entre las mujeres. Sin embargo, el DES se identificó como tóxico para estas poblaciones y se relacionó con un mayor riesgo de cáncer tanto en las madres como en los bebés expuestos al DES. El análisis de Sze es un ejemplo de cómo se disuelven los límites de lo corporal y natural con lo tecnológico, lo artificial y lo sintético (2006).

Tal propuesta enfatiza que los humanos no somos los únicos en agenciar las redes globales, los actantes no humanos también son partícipes de estas redes. Un sólo reordenamiento puede configurar las relaciones humanos-animales cambiando condiciones específicas y potenciar la muerte (Braun, 2008). Por tal motivo, centrar el análisis en la porosidad del cuerpo y su posicionamiento social puede ser una herramienta útil para indagar en la exposición desigual de los cuerpos humanos a tóxicos, patógenos y estresores ecológicos que amenazan la vida (Gabrielson y Parady, 2010).

\subsection{Modos de vida y politicidades}

Nuestras acciones y hábitos se encuentran modelados por nuestro posicionamiento dentro de algún entorno socionatural, no obstante, también configuramos los entornos donde habitamos, es una interdependencia productora la cual produce, crea, tiene agencia y estimula la construcción de subjetividades, procesos de apropiación, construcción de territorialidades, sentido de pertenencia, narrativas y conocimientos locales (Pelayo 2020). Está cogeneración implica una zona de contacto de multiplicidades entre lo humano y lo no humano donde se aglutinan esferas biológicas, sociales, naturales tecnológicas, políticas y culturales que posibilitan la configuración de los sistemas de vida, esto nos remite a pensar en la dimensión ecosomática como herramienta para detallar las ontologías relacionales humano-ambiente.

Pelayo (2020) afirma que en el proceso de esta interdependencia entran en operatividad ciertas formas de sustento, afrontamiento y resistencias que posibilitan el ejercicio de micropolíticas ejercidas dentro del encuadre poder-espacio-tiempo donde los actores se involucran en acciones cotidianas para posibilitar su existencia y la habitabilidad de un entorno vivible.

Para Bardet (2019) profundizar desde el enfoque relacional nos orienta a pensar en el cuerpo "entre, con, como gestos, esta perspectiva nos permite abarcar una continuidad entre corporeidades, medio ambiente, creación técnica, organización social, modos de vida, manera de sentir-pensar etc"(2019, p. 97). Este enfoque relacional nos orienta a pensar en los modos de vida que comprenden el ambiente, el cuerpo y la mente y que alcanza un rango de operatividad micropolítico. Para Pelayo (2020) los modos de vida son: 
y la vida no humana (molecular, mineral, animal, vegetal), en determinado ecosistema y temporalidad. Tales relaciones quedan manifestadas en estilos, prácticas, costumbres, saberes, narrativas, imaginarios, afectos y formas de habitar un espacio geográfico de los individuos o grupos sociales. Esto revela que las prácticas están definidas por una circunstancia contextual (el piso ecológico, los procesos históricos, el momento socioeconómico y las relaciones de poder) articulada a entramados multiescalares que simultáneamente configuran material y simbólicamente la forma de existir de los actores y el habitar un espacio que van configurando un territorio. Los modos de vida dan cuenta de cómo se lleva a cabo la reproducción de la vida de un grupo humano material y existencialmente. Los modos de vida no se reconfiguran per sé, son producto de la interdependencia de los actores con otras formas de vida no humana y el entorno. Es vivir en un lugar de forma inacabada. Son la expresión y el contenido vital de un territorio como totalidad (Pelayo, 2020, p. 83).

Los modos de vida como categoría transdisciplinar y dinámica, viabilizan la observación de diversas facetas vitales y coevolutivas de lo humano y lo no humano, expresan procesos de apropiación, resignificación y reconfiguración de prácticas y entornos materiales en las formas de habitar, aprovechar y vivir los entornos. Tales gestos, están encarnados por los ritmos, las tendencias políticas, económicas, sociales y culturales globales. Para Haesbaert (2011) los modos de vida dan cuenta de la interdependencia de los cuerpos y los flujos de la naturaleza.

Los modos de vida informan de cómo se lleva a cabo la reproducción de la vida de un grupo humano material y existencialmente en interdependencia con lo no humano. También representan las micropolíticas que posibilitan dar continuidad a los sistemas de vida, las cuales pueden influir en resultados positivos o negativos para la sustentabilidad de la existencia humana, debido a que se conforman por mundos sensibles y por las influencias de flujos macro y microestructurales. La categoría de modos de vida despliega las prácticas sociales y relacionales de lo humanono humano y su significado debido a que están atravesados por dinámicas políticas, poderes, discursos y fuerzas translocales y globales que se encarnan en los espacios locales. La dimensión corpórea y existencial, generan conductas; cambiantes y circunstanciales, así como, valorizaciones vitales que van encaminadas a perpetuar la existencia humana.

En tal sentido, los modos de vida son formas de politicidad, prácticas cotidianas a partir de las cuales los actores ejercen acciones y tienen la capacidad de incitar, inducir, facilitar o restringir algo en vías de hacer frente a dinámicas, intervenciones o tendencias que amenazan la posibilidad de vida. En este trabajo la politicidad según Naír Calvo (2002) son las sensibilidades políticas de las o los actores, a sus creencias, actitudes y formas de relacionarse con los debates y decisiones de la esfera pública. Este término está estrechamente vinculado a la cultura política, la politicidad da cuenta de la forma en que la cultura política es incorporada en/y por las y los actores.

Según Naír (2004) la politicidad ocurre en el sedimento de las experiencias de los sujetos en diferentes ámbitos que tienen su propia historia estructural que condiciona las prácticas y percepciones y sucede también en el marco de las condiciones actuales dadas por la estructura organizacional dentro de la que desarrollan sus actividades cotidianas. Para Rodríguez (2010) la politicidad ocurre entre la cotidianidad y la agencia, es parte de la acción de los sujetos. 
Por su parte Isla (2006) afirma que son disposiciones subjetivas hacia determinadas posiciones respecto del poder, la autoridad y la jerarquía. La politicidad da cuenta de la especificidad de lo político en el entrecruce con otros dominios de la vida social, son las condiciones que alojadas en la vida cotidiana de los sujetos orientan sus disposiciones subjetivas hacia determinadas posiciones respecto del poder, la autoridad y la jerarquía (Rodríguez, 2010).

Aunado a lo anterior, la politicidad incluye, comprende y organiza a las formas en que los sistemas públicos de símbolos, textos y prácticas "representan un mundo y a la vez, dan forma a los sujetos de una maneja ajustada a la representación de ese mundo" (Ortner, 2005: 34). La politicidad se subsume en una especie de agencia que también se despliega en la disputa por los recursos, sin embargo, esta no sólo depende de la politicidad de los sujetos sino también del contexto concreto en la que los sujetos se insertan.

\subsection{Poder como productor. Anatomopolítica y biopolítica}

Las sensibilidades políticas no escapan de la presencia del dispositivo del poder, sin embargo, es buen momento para considerar que el poder no siempre esta vinculado con la acción de reprimir o prohibir. El poder se vuelve productor, los mecanismos del poder se caracterizan por la alianza entre el placer y el poder, el poder aquí no esta precisamente ligado a la represión sino a la producción (Foucault, 1979). El poder también funciona produciendo placer y moviliza el deseo. El ejercicio del poder debe ser pensado y reconocido en su sentido positivo que gestiona y administra produciendo, haciendo vivir o dejando morir, genera subjetividades que hacen que cualquier individuo introyecte positiva y micropolíticamente mecanismos de disciplina y vigilancia (Filosofía del pórtico, 2020). Según Foucault (1984) en la medida que el poder se involucra en las cosas, se debe distinguir como se ejerce sobre ellas y otorga la facultad para modificarlas, usarlas, consumirlas o destrozarlas, es un poder que reposa sobre actitudes inherentes al cuerpo o subyacentes con instrumentos externos.

El ejercicio del poder es un estructura total de acciones dispuestas para producir posibles acciones: incita, induce, seduce, facilita o dificulta. En un extremo, constriñe o inhibe absolutamente; sin embargo, es siempre una forma de actuar sobre la acción del sujeto, en virtud de su propia acción o de ser capaz de una acción. Según Foucault (1982) en las condiciones de emergencia sanitaria el poder se hace presente mediante la instrumentación y sujeción de los individuos sobre determinados hábitos corporales productivos y reproductivos desde la microfísica del poder. Según el autor, los modos en que el ser humano se ha convertido en sujeto son a partir de tres modos de objetivación a partir de la ciencia, la economía y la biología. En esta última es posible desplegar cómo se ejerce un poder sobre los cuerpos de las personas, su salud, su vida y su muerte mediante la institucionalización de estructuras legales y regulaciones. La sublevación del cuerpo encontrará una nueva forma de inversión que no se presenta ya bajo una nueva inversión o bajo la forma de control- represión, sino por control- estimulación (Foucault,1979).

El poder no se tiene, se ejerce, existen varios poderes o formas de sujeción, según Foucault a inicios del capitalismo aparecen dos técnicas importantes para analizar el poder: por un lado, la anatomopolítica como mecanismo de poder por el cual alcanzamos a controlar el cuerpo social, y la individualización del poder a través de la vigilancia. Esto, a partir de instituciones del cuerpo 
social como el ejército, la escuela, el hospital, la cárcel y la familia, donde se producen hábitos corporales, gestos, que vuelven a los cuerpos cada vez más dóciles, predecibles y calculables. Por otro lado, la técnica biopolítica la cual manifiesta que el poder se ejerce sobre un grupo de seres vivos atravesados por procesos de leyes biológicas (natalidad, mortalidad, curva etaria, estado de salud, etc.). El poder se ejerce sobre los individuos mientras se comprende que puede ser una población utilizada como máquina de producir riquezas, bienes, otros individuos etc. Esto es la capitalización de la vida donde el cuerpo y la vida pasan a ser objeto del poder. Para finalizar es importante comprender que las relaciones de poder están enraizadas en el sistema de redes sociales, la posibilidad de acción sobre la acción de otros es coextensiva, entrecruzada en ocasiones se contradice o se refuerza.

\section{Metodología}

El alcance de la investigación es de tipo explicativo porque buscó responder las causas de los eventos físicos o sociales y se centró en explicar por qué ocurre un fenómeno, en qué condiciones se da, o por qué dos o más variables están relacionadas. El presente es un artículo teórico que se llevó a cabo bajo una investigación periodística y documental, así como la revisión crítica y la puesta en operación de enunciaciones teóricas formuladas desde la ecología política de la salud y la geografía de la salud, donde se revelaron diversas experiencias y prácticas, pero sobre todo tendencias propias del periodo de pandemia desde los condicionamientos registrados en dos marcadores: la dimensión material y la dimensión inmaterial.

En la dimensión material se profundizó en las formas en cómo se reorganizaron las actividades cotidianas "visibles" en determinación con el contexto, entre ellas, las formas de sustento, los mecanismos para afrontar la pandemia y los tipos de resistencias. Donde el cuerpo se encuentra en contacto directo y coevoluciona en interdependencia con el espacio y las diversas formas de vida no humana quedando de manifiesto en prácticas, estilos, costumbres y formas de habitar el marco espacio-temporal pandémico, en vinculación con entramados multiescalares que comprenden desde lo corpóreo hasta lo global. Tales gestos se encarnaron en mecanismos de vigilancia y control, hábitos, trabajo, consumo, la materialidad del cuerpo, los condicionamientos del espacio y las nuevas formas de habitarlo.

En el marcador inmaterial se registraron gestos que rebasaron la materialidad del cuerpo y alcanzaron dimensiones emocionales, morales y subjetivas, las cuales redefinieron la condición de integridad, capacidad política y social de los habitantes. Tales gestos se manifiestan en la dimensión sensible, afectiva, cognitiva, estética, social y política.

Las técnicas de análisis y las fuentes que dieron cuerpo al presente trabajo se concentraron en el análisis de contenido de los documentos periodísticos donde se examinaron noticias sobre la trayectoria y las tendencias de consumo durante el periodo de pandemia, también se revisaron informes de algunas instituciones nacionales y latinoamericanas de investigación como la Universidad Nacional Autónoma de México (UNAM), el Consejo Nacional de Ciencia y Tecnología (CONACYT), la Dirección General de Epidemiología (DGE) y la Comisión Económica para América Latina (CEPAL). Las cuales proporcionaron resultados de investigaciones preliminares sobre diversos temas como: el contexto epidemiológico desde los contagios generados por COVID-19, el análisis de la dimensión ambiental como las tendencias de consumo de productos 
de sanitización, la condición de los recursos naturales en el contexto de pandemia, la generación de residuos y las nuevas formas de contaminación. Por otro lado, se revisaron documentos y páginas que detallaron estadísticas de casos por COVID-19, fallecimientos, así como el avance de la producción y aplicación de vacunas.

Cabe recordar, que este trabajo se construyó bajo la ruta y estructura de articulo teórico, por tal motivo se suman a la investigación periodística y documental la experiencia situada de la autora y la profundización del análisis crítico de enunciaciones teóricas vinculadas a la ecología política de la salud y la geografía de la salud en asociación con las categorías principales de este estudio como son los modos de vida, las formas de politicidad y el poder que imperaron en el corte temporal de análisis de este trabajo que comprendió de febrero 2020 a septiembre 2021. Tales ensamblajes posibilitaron la construcción de un bosquejo de elementos que componen la sección del desarrollo de este artículo y los marcadores principales como la dimensión material y la dimensión inmaterial los cuales fueron identificados en las tendencias y condicionamientos del periodo de pandemia por COVID-19.

\section{Reordenamientos del régimen pandémico}

\subsection{El contexto}

El 31 de diciembre de 2019 se registró el primer brote de enfermedad por coronavirus (COVID-19) en Wuhan (China), el 27 de febrero de 2020 se anunció el primer contagiado por COVID-19 en México. A 15 de agosto se habían registrado 201 millones de casos de coronavirus (SARSCoV-2) en el mundo, en México se estimaron 3382683 de casos positivos (Dirección General de Epidemiología, 2021). A principios de agosto de 2021 se contabilizaron 4,3 millones de muertes por el virus a nivel global, encabezando la lista de muertes el continente americano con 2247 792 personas fallecidas, seguido de Europa con 1334 980, Asia 1055 631, África 213946 y Oceanía con 3.409 personas fallecidas (Statista a, 2021). El país que encabeza la lista de muertes por este virus es Estados Unidos al superar los 730.210 decesos, seguido de Brasil con alrededor de 599.865, después India con 450160 y por último México con 281121 (Statista b, 2021).

El 08 de diciembre de 2020 fue aplicada la primera vacuna validada por la OMS financiada por la farmacéutica estadounidense Pfizer en colaboración con BioNTech. En febrero de 2021 también se incluyeron las vacunas Covishield del SIl y la vacuna AZD 1222 AstraZeneca (desarrolladas por AstraZeneca/Oxford y fabricadas por el Serum Institute de la India y SK Bio, respectivamente), después el 12 de marzo se incluyó en el listado la vacuna Janssen/Ad26.COV2.S desarrollada por Johnson \& Johnson. El 30 de abril se añadió a la lista la vacuna mRNA-1273 de Moderna, y el 7 de mayo, la vacuna de Sinopharm el 1 de junio se autorizó la vacuna Corona Vac de Sinovac (Organización Mundial de la Salud, 2020). A la fecha del 12 de agosto de 2021 los procesos de vacunación se encontraban de la siguiente manera: Chile con $82.6 \%$ de vacunas administradas, China con $78.6 \%$, seguido de España con $75.1 \%$, Canadá con $74.6 \%$, Francia con $72.4 \%$ Reino Unido con 70 \% y México con un $38.9 \%$ de cobertura en vacunación (EL CEO, 2021).

La condición de pandemia por COVID-19 no tardó en trastocar diversos nichos de mercado y el perfil de los consumidores, ocasionando una mercantilización de la prevención del virus. Los comportamientos de consumo cambiaron de topología desplazándose de compras presenciales a e-commerce o compras en internet. Según Mercado Libre en Latinoamérica la condición de 
pandemia registró más de 1.7 usuarios nuevos en la plataforma digital en marzo de 2020. Los productos con mayor búsqueda fueron tapabocas (10 millones), alcohol en gel ( 8.5 millones), antibacteriales (3.5 millones) y termómetros (1 millón) (El Tiempo, 2020). Según un estudio en 2020 el comportamiento del consumo por los mexicanos fue el siguiente un $74 \%$ adquirieron productos sanitizantes/desinfectantes, $54 \%$ productos de limpieza en general, $36 \%$ productos frescos: frutas, verduras, carnes, etc., $37 \%$ gastos en salud como medicamentos, citas médicas, exámenes etc., 30\% despensa: pasta, arroz, enlatados, café, etc., 26\% cuidados e higiene personal y $29 \%$ suplementos alimenticios y vitaminas (Editorial, 2021).

\subsection{Hacia una sociedad aséptica}

Hasta ahora, es poca la información ambiental, sociocultural, política y económica que se ha registrado sobre las tendencias mercantiles, sociales y políticas derivadas del COVID-19. Sin embargo, es posible observar y experimentar diversas prácticas y hábitos incorporados en los últimos veintiún meses desde que se registró el primer caso de COVID-19 en el país. Experiencias como el estudio de Braun (2008) sobre la aparición del SARS en las ciudades de Hong Kong, Toronto y Taipéi otorgan pistas de cómo se experimentó el virus en términos socioculturales donde las prácticas más visibilizadas abarcan desde la presencia de objetos y gestos como: máscaras quirúrgicas en tranvías, el “distanciamiento social” en eventos públicos, la evitación de los espacios públicos como los aeropuertos y hospitales.

En Toronto se presentó un fenómeno propio del terror viral, la estigmatización de los restaurantes chinos, además, se implementó el uso de técnicas como aspiración y gotitas respiratorias las cuales trazaron colectivamente los contornos de los cuerpos en términos de una geografía a escala molecular. Braun (2008) afirma que se configuró el entendimiento de las ciudades como espacios biosociales complejos e impredecibles, donde consecuentemente se implementaron normas y prácticas encaminadas a regular los movimientos, e intercambios del cuerpo con otras entidades.

El régimen pandémico tiene componentes que potencian determinados modos de vida y gestos políticos que componen una atmósfera de miedo al contagio por COVID-19. Los mecanismos discursivos, por ejemplo, alcanzan dimensiones políticas y subjetivas que han maquinado modos de ser, habitar, pensar y vivir dentro del marco temporal pandémico, estimulando a las sociedades a re-subjetivar y practicar diversas representaciones, ideales, expectativas y estilos de vida basados en el temor al contagio. También en un tipo de estado de amedrentamiento emocional y moral de la sociedad, el cual terminó por modular y controlar sociopolíticamente a las poblaciones, así como, la materialidad de los cuerpos en vías de procurar el resguardo de la vida.

Tales condiciones instauradas en un marco temporal pandémico y en un entorno de encierro físico y subjetivo, operan como máquinas de producción, reforzadas por instrumentos mediáticos, equipamientos de la vida social e instituciones (Guattari, 2008). Asimismo, desocultan contradicciones, deficiencias, obsesiones, procesos discriminatorios y diversos tipos de violencia y ascetismos corporales e ideológicos que confeccionan una sociedad aséptica atravesada por el poder, un poder no precisamente ligado a la represión, sino a la producción (Foucault, 1976). 
Según Han (2021) sólo el régimen represivo provoca la resistencia, el régimen neoliberal, no oprime la libertad, sino que la explota, no es represor sino seductor, la dominación se completa al momento que se presenta como libertad. Es así como la posibilidad de ser participes activos de nuestra propia subordinación y control biopolítico se presenta de forma discreta y sutil.

La sociedad aséptica se basa en el individualismo cimentado en la evitación del otro por la posibilidad de ser un posible vector de contagio, encuentra el sosiego en una obediencia incuestionable y acrítica a las normativas de estado o de la esfera de la salud porque está convencida de que las instituciones implementan los mejores mecanismos y políticas para su pervivencia. El sujeto de la sociedad aséptica se aliena de la realidad social y política y camina bajo la norma de salubridad estatal y global, llegando así a una totalización del régimen pandémico.

La sociedad aséptica ha sido convencida de que debe mantenerse estéril y pulcra, la maquinaria mediática y las políticas de Estado le han persuadido a tal grado que ha perdido su capacidad crítica y sensible sobre la pandemia. Esto ha posibilitado que la misma sociedad asuma determinadas responsabilidades y promueva su propia inmunidad corporal a partir de un frecuente trabajo personal en busca de su propia salud, higienización y la mínima posibilidad de contaminación corporal que implique el contacto con patógenos o agentes infecciosos. La sociedad aséptica ha configurado modos de vida moldeados por el temor al peligro instalado y reforzado por la estructura institucional y mediática.

Los comportamientos y las sensibilidades confeccionados en el régimen pandémico también están orientados a la pervivencia del sistema capitalista. Se han reconfigurado los ritmos, las sensibilidades, los cuerpos y los procesos de subjetivación, que no siempre están a favor de la preservación de la vida. También manifiestan pulsiones microfascistas, la perpetuación de las relaciones de poder y el autocontrol de los individuos a partir de la lógica biocapitalista que explota y mercantiliza todo tipo de vida.

Durante la investigación se buscaron esquemas de subordinación, resistencias y afrontamiento como recursos que evidenciaron la primacía de un ambiente dominante de disciplinamiento, dominación y control, donde el operador principal fue el temor y la condición de pandemia como productor de prácticas imaginarios y deseos dominados por un poder ubicuo encargado de reordenar sistemática y micropolíticamente la sociedad, de forma casi imperceptible, bajo la primicia del resguardo y la seguridad global. Las configuraciones registradas en este trabajo originadas por la pandemia se manifiestan en dos planos: el material y el inmaterial (Ver tabla 1). 
Tabla 1. Dimensiones materiales e inmateriales

\begin{tabular}{|l|}
\hline DIMENSIÓN MATERIAL \\
\hline VIGILANCIA \\
Vigilancia digital (Uso de dispositivos electrónicos para el monitoreo de \\
signos vitales, síntomas, registros para el ingreso a los espacios públicos). \\
Vigilancia aséptica (revisión de uso de antibacteriales, cubrebocas, sana \\
distancia y vacunación). \\
Vigilancia y monitoreo laboral (Celulares, computadoras y tabletas) \\
Registro de bioidentidades (identificación en páginas a partir de datos \\
biométricos).
\end{tabular}

\section{HÁBITOS}

Hiper-higienización (habituación del uso de productos higienizantes, antibacterianos, antivirales y farmacéuticos)

Disponibilidad productiva permanente (ejercicio laboral en horarios indefinidos y atención permanente vía celulares).

Reducción del tiempo de vida y el esparcimiento por home office.

Intensificación de la espectacularización de la vida íntima- El show del yo.

Hiperconectividad

\section{TRABAJO}

Nuevo culto laboral de hiperconectividad y productividad.

Trabajo doméstico indefinido (agudización de la triple jornada para mujeres). Dislocación de espacios productivos (hogar como lugar de trabajo y espacio de vida, computador y celulares como nuevos territorios productivos).

Dislocación de tiempos productivos (disponibilidad absoluta).

Precarización y expoliación laboral (explotación, productividad sin interrupciones bajo la consigna de aprovechar el tiempo).

Transformación de la potencia de vida en capital de trabajo.

\section{CONSUMO}

Infodemia (Consumo exacerbado de información sobre pandemia).

Hiperconsumo de productos sanitizantes (tapabocas, botellas antibacterial, guantes, multivitamínicos).

Marea plástica y generación de desperdicios (aislamiento de alimentos, productos desechables: mascarillas, guantes, cubiertos).

Aumento de consumo del Fast food

Mercantilización de la vida- lo vivo reducido a un recurso o capital (Aumento de venta de seguros de vida y paquetes funerarios).

Fenómeno Delivery (entregas a domicilio)

Mayor uso de recursos hídricos para procesos de higiene y sanitización.

\section{CUERPOS}

Prácticas para lograr la inmunidad corporal y autoconservación: dieta sana, ejercicio y la ingesta de sustancias químicas como vitaminas y suplementos. Rehuir del cuerpo (evitar tocar ojos, nariz y boca).

Regulación y/o nulidad de intercambios con otros cuerpos.

Dismorfias corporales (filtros web que determinan parámetros estéticos distintos a la naturaleza del cuerpo natural).

Auto-monitoreo vital rutinario (uso de oxímetro, chequeo de temperatura). Hiperestimulación del sistema nervioso y visual por el uso de pantallas.

Metabolismos lentos por cambios motores y aumento de peso.

Crisis de ansiedad.

Envejecimiento prematuro y pigmentación por pantallas.

Tensión acumulada por inactividad física.

Afectación ocular por exposición a pantallas.

Mayor consumo calórico por condición de "quédate en casa"

Alienación corporal (centralismo de la actividad ocular y mental sobre la movilidad corpórea).

\section{ESPACIO- HABITABILIDAD}

Home office y monoambientes (encierro a cielo abierto-mismo lugar para comer, trabajar y dormir). Vida en la virtualidad (habitar la realidad virtual). Evitación de los espacios públicos.

Habitar el espacio desde la sana distancia.

Topografías del encierro y reconfiguración somática (posiciones corporales, procesos metabólicos y rutinas de habitabilidad moldeadas por las

condiciones materiales del espacio de encierro- continuidad cuerpo hábitat).

\section{DIMENSIÓN INMATERIAL}

\section{SENSIBLES}

Resignificación de la condición de hogar como espacio de encierro y espacio de resguardo biosocial.

Nuevos órdenes estéticos basados en la hiperestimulación de las pantallas (colores, temperaturas y brillos).

Cultura de la vulnerabilidad (Temor permanente al contagio, al riesgo y a la catástrofe). Terror social, miedo a las congregaciones y encuentros sociales.

Privación de necesidades y deseos presentes para augurar el futuro (normativas y políticas de salubridad y encierro).

Banalización y desensibilización de la muerte por pandemia (reconfiguración de los umbrales de empatía sobre la muerte debido a la masividad de fallecimientos).

\section{AFECTIVOS Y SOCIALES}

Resignificación de la vida y la muerte a partir de la incertidumbre del riesgo pandémico y la masividad de fallecimientos.

Abyección y desconfianza del otro como posible vector de contagio (si tuvo COVID-19 o si ya fue vacunado).

Devenir encierro (nuevas formas de coevolución con el espacio doméstico, encarnamiento de la condición del encierro a nivel emocional).

Quebrantamiento físico y moral de los ciudadanos, apropiación de la condición de vulnerabilidad por el riesgo pandémico.

Hiperconexión (socialización en la virtualidad).

Enemigo invisible - desconfianza del otro como posible vector de enfermedad.

Ciudadanos panópticos (Acatar leyes y vigilar que otras y otros las cumplan ante la urgencia sanitaria)

Sistema separatista por el riesgo a ser infectado debilitamiento de capacidad de determinación política de los ciudadanos.

Reconfiguración de formas de sociabilidad y manifestación afectiva basada en la "sana distancia”.

\section{COGNITIVOS}

Producción y activación de nuevas destrezas para habitar el encierro.

Incorporación de saberes de higienización y adiestramiento para la evitar el riesgo pandémico.

Producción y adaptación de nuevas representaciones de la salud provenientes de instituciones del sector salud.

Reproducción subjetiva de la pandemia a partir del consumo masivo y acrítico de

información sobre la seguridad sanitaria.

\section{ESTÉTICOS}

Asepsia frenética, para alcanzar la higienización corporal.

Cultura del enmascaramiento (incorporación de la mascarilla como símbolo de salud, protección y seguridad colectiva).

Espectacularización del encierro (exhibición de las formas de habitar la pandemia por redes sociales que normalmente deviene de grupos con alto poder adquisitivo).

Ideales ascéticos (sacrificio, purismos, despreciar los metabolismos y deseos del cuerpo-negar la potencia de vida)

Espectacularización y estetización del confinamiento.

\section{POLITICIDADES}

Racismo sanitario (juicios de valor por tipo de vacuna, contagios previos, zona de residencia y condición geográfica del semáforo pandémico).

Legitimidad de los rostros cubiertos (sensación de mayor seguridad y salubridad por e sujeto enmascarado ).

Reconstitución del "sujeto virtual" a partir de las bioidentidades (registro de datos biométricos para abrir redes sociales).

Estimulación de "buen ciudadano" acrítico (sujeción a prácticas que no se cuestionan donde impera la moralidad).

Terror sistemático y construcción social del miedo (manipulación psicológica y moral por miedo al contagio).

Fidelidad plena a las normas institucionales de salubridad como mecanismo ante la emergencia sanitaria.

Microfascismos (sanción social a quien no cumple las normas pandémicas, abyección del otro).

Política de la paranoia (ejercer el principio precautorio con prácticas y hábitos compulsivas de autocuidado e higienización para augurar la inmunidad presente futura). 


\subsection{Dimensiones materiales}

\subsubsection{Vigilancia}

En la categoría de vigilancia se registraron practicas orientadas al gobierno de los mismos ciudadanos (gobierno de sí), condición estipulada por marcos biopolíticos normativos de instancias de salud para controlar los posibles eventos de riesgo en el cuerpo social. Sin embargo, estas practicas también fueron reforzadas por la infraestructura mediática, se encarnaron como parte de los hábitos de los ciudadanos para disminuir las conductas de riesgo. Esta introyección se ejerció mediante por dispositivos tecnológicos como celulares, y laptops, los cuales operan como mecanismos de custodia de los signos vitales. Mediante registros usados para el ingreso a diversos espacios de comercio como medio de localización de posibles focos de contagio, donde los signos vitales y la vida misma se volvieron inteligiblemente virtuales.

En cuanto a la dimensión laboral, los dispositivos electrónicos se convirtieron en una extensión espacial y temporal más de nuestro territorio laboral y productivo, así como, en artículos de culto, donde las actividades laborales de localización, monitoreo y vigilancia productiva se puede hacer permanentemente. En cuanto a la vigilancia aséptica se logró observar como la misma ciudadanía fungió como custodia de ella misma, al observar y asegurar que los demás ciudadanos utilizaran y cumplieran con los requerimientos de salubridad e higienización. En esta situación se observa como se introyectan las micropolíticas del poder con las prácticas morales y de higienización y además se aprecia cómo los ciudadanos se convirtieron en los custodios y promotores más efectivos para la consolidación del nuevo orden social.

\subsubsection{Laboral}

Estos nuevos cultos laborales de hiperconectividad, productividad y la disponibilidad permanente que implicaron el home office vinieron a intensificar las horas de trabajo y a dislocar los tiempos y la espacialidad de los lugares productivos como lo fue el trabajo desde casa que también operó como espacio de convivio y de descanso. Tal modificación estimuló una mayor carga de trabajo y precarización física de los cuerpos por la productividad sin interrupciones, en esta ocasión la arquitectura económica dispuso totalmente de los tiempos de los recursos humanos para la continuidad del sistema productivo.

\subsubsection{Hábitos}

Los procesos, las prácticas cotidianas, los estilos de vida se modificaron para evitar el riesgo. Se observó la incorporación de prácticas higienizantes compulsivas en vías por alcanzar la salubridad necesaria, desde la modulación de su conducta, la dieta, el estilo de vida, la ingesta de medicamentos, modelando ciudadanos biológicamente responsables de su riesgo o su contagio. Se observó una híper-higienización con productos antibacteriales y la medicalización, así como la dislocación laboral que aumentó las actividades productivas y una disponibilidad permanente del trabajador incidiendo en la disminución del tiempo de vida o de ocio. Otro de los hábitos emergentes fue la espectacularización de la vida íntima, el confesionario digital se robusteció con la hiperconectividad mediante los aparatos tecnológicos y el uso de las redes sociales. 


\subsubsection{Consumo}

Los hábitos de consumo se reconfiguraron a la luz de la condición de pandemia, esto fue reforzado por campañas relacionadas con la salud y la higiene. La categoría de consumo fue una matriz de parámetros excluyentes, no cualquiera pudo acceder a determinados servicios o ingestas debido a la crisis económica que causó la pandemia. En general los consumos fueron a la alza, la condición de pandemia generó una paranoia de incertidumbre y activó la economía del mercado de la salud mediante el consumo de víveres, sustancias higienizantes y materiales aislantes para reducir el contagio.

También se observaron otros consumos ante la efervescencia mediática de la situación de pandemia como la infomedia (Sánchez y Valdés, 2020). Consistió en la búsqueda compulsiva de información que ofreciera alguna estrategia, ruta de acción para evitar el contagio. La condición pandémica consolidó rituales de aislamiento social pero también aislamiento material del cuerpo con los objetos. Los plásticos dominaron esta acción aislante, se observaron mareas de productos plásticos para sellar, esterilizar y aislar cualquier elemento que pudiera ser contaminado, aumentando el nivel de desechos (Dirección General de Comunicación Social, 2021). También en la industria de la salud se evidenció la intensificación de la demanda de seguros de vida (González, 2021) incluso algunas aseguradoras tuvieron exceso de solicitudes de servicios funerarios (Forbes, 2021) generando una mercantilización de la vida, donde la condición de lo vivo fue reducida a un recurso o capital.

Por otro lado, el fenómeno Delivery fue un servicio que creció en la pandemia, la ciudadanía prefirió encargar sus víveres en lugar de arriesgarse al contagio, fue la entrega a domicilio de alimentos, servicios de paquetería y la compra-venta en línea (El economista, 2021). En cuanto a el uso de recursos naturales, uno de los recursos más utilizados fue el hídrico, el agua fue necesaria para procesos de higienización y sanitización tuvo una alta demanda, situación que también reveló las desigualdades hídricas y la crisis de agua en algunos espacios geográficos (CEPAL, 2020; Toche, 2021).

\subsubsection{Cuerpos}

El cuerpo se encuentra en contacto directo y coevoluciona en interdependencia con el espacio y las diversas formas de vida no humana. El cuerpo fue el dispositivo con mayor vigilancia, modulación, disciplinamiento y supervisión; inicialmente bajo diversas técnicas disciplinarias o normativas de salud, escolares, gubernamentales que lo colocaron como un lugar de riesgo biológico. Según Foucault para la sociedad capitalista lo importante es lo biológico, lo somático y lo corporal. El biopoder no se puede afirmar sino es con la inserción controlada de los cuerpos en el aparato de producción y mediante ajustes de fenómenos de población a los procesos económicos (Foucault, 1996). Esta aspiración implica proteger el cuerpo social, regular, y potenciar su vida para el mantenimiento y expansión del capitalismo. La materialidad de los cuerpos ya no se puede concebir fuera de la norma, la discursiva, la política y el hábitat del imperativo pandémico, la regulación de los cuerpos se volvió un engranaje indisociable del régimen pandémico. 
Lo anterior se hace constar que a partir de las prácticas de inmunidad corporal el mismo sujeto emprendió acciones para lograr su propia conservación; tales como, mejorar su alimentación, practicar ejercicio, ingerir multivitamínicos y hasta sacrificar o modular ciertos deseos. El cuerpo también estuvo monitoreado para detectar algún riesgo fisiológico mediante el uso regular de aparatos que evaluaron los signos vitales como: oxímetros y termómetros. Por otro lado, se observó un distanciamiento de intercambios con otros cuerpos, así como, dismorfias corporales por la predominancia de tendencias del medio virtual y los filtros de las redes sociales. Esta predominancia virtual también causó una hiperestimulación del sistema nervioso y visual, además de la ralentización de los metabolismos y el aumento del consumo calórico por la condición de encierro en casa, crisis de ansiedad, envejecimiento prematuro por la pigmentación de las pantallas, así como la alienación e inactividad motora por un centralismo ocular y mental del cuerpo.

\subsubsection{Espacio-habitabilidad}

Las formas de habitar el espacio doméstico y público cambiaron, los individuos se adaptaron al espacio, de encierro y de pandemia. El cuerpo social está constituido por sistemas extracorporales, el medioambiente, la cultura y cómo se experimenta el entorno, condiciones que constituyen nuevas formas cohabitar o devenir "con" (Haraway, 2008). Gabrielson y Parady (2010) afirman que la experiencia de habitar en diversos entornos sociales y naturales tanto discursivos y materiales da forma a la subjetividad y la condición. El lugar es un entorno, sin embargo, la noción de entorno trasciende a ser experiencial y relacional. En esta lógica las modificaciones de la pandemia como el home office moldearon la constitución de los sujetos su relación y organización de los cuerpos con el hábitat. La vida en la virtualidad moduló los ritmos, morfologías corporales y mentales, además encarnó estilos de habitabilidad basados en la sana distancia y reconfiguró topografías de encierro desde lo somático hasta las posiciones corporales, los procesos metabólicos, las rutinas de sumisión corpóreo-mentales, así como la conformación de la extensión del cuerpo-hábitat a la luz del encierro.

\subsection{Dimensiones inmateriales}

En el marcador inmaterial se lograron registrar diversos gestos que rebasaron la materialidad del cuerpo y alcanzaron dimensiones emocionales, morales y subjetivas, las cuales redefinieron la condición de integridad, capacidad política y social de los habitantes. En este apartado se registraron ciertos imaginarios, afectos, narrativas y discursivas asociadas a los territorios existenciales (Guattari, 2008). Se analizan los aspectos discursivos e ideológicos como las prácticas discriminatorias, criminalizadoras, fundamentalismos, afectos, la producción de subjetividades y otras expresiones. Tales gestos se manifiestan en las categorías: sensibles, afectivas y sociales, cognitivas, estéticas y las formas de politicidad.

\subsubsection{Sensibles}

Dentro de esta categoría se observaron aspectos que expresan un cambio en las dimensiones psicosociales y en lo emocional; desde la resignificación del espacio de encierro como un resguardo biosocial, reforzado por el terror social, el miedo a las congregaciones o encuentros sociales. Lo cual consolidó una cultura de vulnerabilidad basada en el temor permanente al 
contagio, el riesgo y la catástrofe. Una dimensión asociada a estas prácticas se generó con la privación de necesidades y deseos presentes para augurar el futuro, entre ellas la incorporación incuestionable de normativas de salubridad, higienización, bioseguridad y sobre todo el encierro.

También se observó la aparición de nuevos órdenes estéticos basados en la hiperestimulación de las pantallas (colores, temperaturas y brillos), no obstante, también se visibilizó la banalización de la muerte (Hernández y Pelayo, 2020) ante los nuevos umbrales de contagios y fallecimientos que han reconfigurado los gestos de empatía y han generado la resignificación de la vida y la muerte.

\subsubsection{Afectivos y sociales}

Para la dimensión afectiva retomamos la propuesta de Spinoza (1987) que asevera que un individuo, un cuerpo, se define por las afecciones que mantiene con los demás cuerpos y por su poder de ser afectado, así pues, un afecto es lo que le puede suceder a un cuerpo y lo que lo define. Es decir, cada uno de estos afectos posee un umbral máximo y mínimo que corresponden a un aumento de potencia o a una descomposición. En tal categoría se registraron diversas manifestaciones que moldearon las formas de concebir la vida, la muerte y nuestras formas de asumirnos y relacionarnos. Inicialmente el devenir encierro constituyó nuevas formas de coevolucionar con el espacio doméstico, así como introyectar el encierro a nivel emocional y social. Se generó un sentimiento de abyección o desconfianza del "otro" como posible vector de contagio en caso de haber tenido COVID-19, o estar vacunado, también la condición de vulnerabilidad generó otros sentires como el quebrantamiento físico y moral del cuerpo social (Hernández y Pelayo, 2020) por la posibilidad de contagio.

El aislamiento físico y emocional estuvo presente, se concretaron situaciones propias de la paranoia pandémica como la desconfianza y el espectro del enemigo invisible como posible vector de enfermedad que en ocasiones estímulo situaciones de anti-colaboración por el riesgo al contagio. También se observó la actuación de los ciudadanos panópticos que acataron todas las normativas y desempeñaron funciones de vigilancia hacia los demás para que acataran las normas higiénicas, estas acciones consolidaron nuevas formas de sociabilidad y afectos basados en la "sana distancia".

Pese a este nivel de aislamiento y distanciamiento un fenómeno que tuvo su explosión fue la hiperconexión, la cual se instaló como un hábito y una forma de relacionarnos mediante las redes sociales, donde se emprendieron rutas de socialización, trabajo, exploración, compra, consumos y adiestramiento conformando el protagonismo del yo epidérmico dúctil (Sibilia, 2008) como una extensión más de la máquina social y productiva.

\subsubsection{Cognitivos}

La producción de destrezas posibilitó sobrellevar la situación de encierro y de la pandemia de diversas formas como mecanismos de resistencia y afrontamiento. Dentro de los nuevos marcos cognitivos a los cuales tuvimos que adaptar nuestra vida se observó la incorporación de saberes de higienización y adiestramiento para evitar el contagio, la producción de nuevas representaciones de lo que significaba la salud a partir de lo que la estructura mediática e institucional informaba: situación que también generó la reproducción subjetivada de la pandemia por el consumo masivo y acrítico de la información circulante (infodemia). 


\subsubsection{Estéticos}

Las representaciones y percepciones estéticas tuvieron cambios importantes, una de ellas fue la aspiración frenética de lograr la asepsia corporal como mecanismo de prevención al contagio. También se experimentó la cultura y preferencia por el enmascaramiento o incorporación de las mascarillas como símbolo de salud, protección y seguridad colectiva. Dentro de estas modificaciones hubo expresiones propias del habitar pandémico como la espectacularización del encierro donde en su mayoría se presentó el show del yo (Sibilia, 2008); es decir la exhibición de cómo sobrellevamos la pandemia en nuestras vida cotidiana mediante las redes sociales. Además, se instalaron algunos ideales ascéticos o sacrificios como mecanismos de minimización del riesgo al contagio epidémico y aspiraciones colectivas para aumentar la salubridad; algunas de ellas fueron la reducción del consumo de alimentos perjudiciales para la salud humana, así como, el control de los metabolismos corporales y los deseos.

\subsubsection{Politicidades}

Al principio resaltamos que el régimen pandémico agudizó ciertas politicidades por habitar el encierro y estar en permanente riesgo. Una de ellas fue el racismo sanitario cimentado en juicios determinados por el tipo de vacuna, la posibilidad de contagio y la zona de residencia. Otra situación muy marcada fue la legitimidad que adquirió el rostro enmascarado como símbolo de seguridad y salubridad, así como, la fidelidad que se entabló entre el cuerpo social y las normas institucionales de salubridad como defensa ante la pandemia por COVID-19. También se observó la reconstitución del sujeto virtual mediante la construcción de ciberidentidades para registrarse en redes sociales, entrar en algunos establecimientos y comercios.

Otros fenómenos expusieron el cómo interiorizamos la norma y la pandemia. Tal fue el caso de la transformación "del buen ciudadano", sujeto a prácticas donde imperó más la moralidad acrítica de la pandemia que la solidaridad con las condiciones de los otros. Esto se generó por el terror sistemático y la construcción social del miedo que se consolidó con la condición de pandemia mediante diversas formas de manipulación psicológica y moral. Lo anterior, nos orienta a pensar en los microfascismos que se generaron en el marco temporal pandémico como el odio y sanción social a quien no cumplía las normas higiénicas, que en conjunto con la abyección del "otro" figuraron como mecanismos de vigilancia y castigo social. Dentro de este campo se consolidó la política de la paranoia esto fue el ejercicio de hábitos compulsivos de autocuidado e higienización para augurar la inmunidad presente y futura como principio precautorio.

\section{Conclusión}

El imperativo de la pandemia quedó inscrito en nuestras vidas bajo diversas manifestaciones, la continuidad cuerpo, hábitat y pandemia se consolidó como ensamblaje a partir de la instalación de hábitos que propiciaron la salud física y moral de la sociedad, mediante diversos aparatos estructurantes como el Estado, los medios de comunicación, las instancias educativas, la familia y las instancias de salud las cuales alcanzaron una mayor legitimidad e influencia para llevar a cabo diversos actuaciones sobre nuestras vidas.

Estos aparatos fomentaron el interés higiénico tanto corporal como mental por parte de los ciudadanos, tales modificaciones se gestaron bajo la condición de encierro, pánico, incertidumbre 
y riesgo. Estos factores potenciaron y afianzaron procesos disciplinantes y de subordinación, que además promovieron la dislocación y resignificación de imaginarios y representaciones de la vida y la muerte ante los nuevos umbrales de contagios y fallecimientos que causó la pandemia por COVID-19.

Dentro de la categoría de configuraciones materiales se observaron diversos gestos y prácticas en las cuales se identificaron fenómenos alarmantes como la introyección de hábitos vigilantes bajo la narrativa de salud y moral, así como, una dislocación y reconfiguración de tiempos, espacios y ritmos productivos lo cual quedó expresa en la condición del home office. Los hábitos consolidaron la ritualización de la higiene material y subjetiva, así como, una espectacularización de la intimidad mediante las redes sociales. Este fenómeno reveló cómo el sujeto se volvió productor y protagonista de su propia narrativa pandémica.

El consumo dejó ver una compulsividad por aspirar a la pureza, higienización, salubridad y aislamiento material del riesgo. Tal fue el caso del uso de mecanismos aislantes como plásticos y papeles lo cual ha generado el incremento de desechos sólidos. Fue de interés observar como la vida se volvió parte de los circuitos de valorización del capital, o capital biológico, con el incremento de seguros de vida, incremento de paquetes funerarios donde la vitalidad o finitud de la vida se convirtieron en potencial de valor. Los cuerpos fueron observados como campo de riesgo de contagio, el cuerpo se convirtió en el espacio material; el espacio material con mayor disciplinamiento y adaptación al entorno bajo diversas medidas donde los individuos nos vimos más adaptados y orillados a la norma de la política del terror pandémico.

El espacio-hábitat evidenció una reorganización corpórea y la interiorización del entorno que moduló nuestras formas de cohabitarlo, pero, sobre todo tuvimos un devenir encierro que instaló determinados ritmos, percepciones y sensaciones que atravesaron nuestra condición morfológica y emocional, encierro que también condicionó temporalmente nuestra agencia social.

El marcador inmaterial se caracterizó por un cambio en la dimensión sensible, tal es el caso de la concepción del espacio de encierro como un sitio de resguardo biosocial. Además, nuestra auto-percepción como sujetos vulnerables, conllevó a una privación de necesidades y deseos que nos expondrían al riego, como el socializar o emprender relaciones afectuosas. También se presentó la banalización de la muerte por la gran cantidad de fallecimientos, la modificación en nuestras formas de relacionarnos desde el miedo con desconfianza y abyección hacía el otro. Y, se introyectaron diversos mecanismos de vigilancia constituyéndonos como ciudadanos panópticos; vigías de los demás. Por otro lado, transitamos hacía la hiperconexión y la hiperestimulación del mundo virtual, en el cual logramos socializar y expresar las formas del sentir el encierro, en un espacio dominante que llenamos con nuestras experiencias y ciberidentidades.

En cuanto a los procesos cognitivos, emprendimos destrezas de sobrevivencia frente de a la pandemia, desde nociones de higienización, adiestramiento al aislamiento y a la sana distancia así como la construcción de nuevos saberes asociados al habitar del encierro. En cuanto a la categoría de lo estético hubo una frenética inclinación a lo estéril y aséptico. La reducción del riesgo al contagio mediante la compulsiva esterilización predominó nuestros rituales de higiene. A esto se suma la incorporación del enmascaramiento en nuestras vidas donde nuestro primer contacto de socialización se redujo a la mitad del rostro; los ojos reforzaron su centralidad 
como dispositivo de reconocimiento y herramienta social. El enmascaramiento se resignificó como dispositivo de seguridad, protección y una especie de política social.

En la dimensión de politicidades se observó el despliegue de un racismo sanitario asociado a la marca de vacuna hasta la posibilidad de haber sido contagiado o tener familiares en esta condición, lo cual desencadenó algunos gestos microfascistas basados en el juicio social. También nos legitimamos en el mundo virtual a partir de la construcción de ciberidentidades como mecanismos de registro para el ingreso al establecimientos y acceso a determinadas redes sociales. Además, nos volvimos expertos en la aplicación de la sanción social sobre el otro que no acataba reglas de seguridad sanitaria, operando como vigilantes de nuestro propia inmunidad.

Las configuraciones observadas en el plano material e inmaterial fueron moduladas bajo mecanismo discursivos, políticos y subjetivos operantes en el marco temporal pandémico y han maquinado nuevas formas de ser, habitar, pensar y vivir. Encauzando a las sociedades a resubjetivar y practicar diversas representaciones, temores, ideales, expectativas y ejercicios que terminan y controlar a las poblaciones y la materialidad de los cuerpos a la luz del resguardo de la vida en la condición de emergencia sanitaria y el gran riesgo por COVID-19.

Tales instauraciones del encierro físico y emocional operaron como máquinas de producción, reforzadas por instrumentos mediáticos, los equipamientos de la vida social e instituciones que manufacturaron gestos y politicidades orientadas a la continuidad de la sostenibilidad de la vida. Pese a que varios gestos, estilos y politicidades implementadas en la pandemia por COVID-19 buscaron la conservación de la vida también visibilizaron deficiencias estructurales, contradicciones de los estilos de vida, procesos discriminatorios, violentos y limitativos, que bajo la narrativa de salvaguardar la vida humana mediante la pulcritud e higiene detonaron gestos propios de una sociedad aséptica; racista y clasista. La continuidad cuerpo, hábitat y pandemia consolidaron una reinvención de nuestras formas de concebirnos como ciudadanos biológicos, pero sobre todo preguntarnos qué significa ser humano a la luz del riesgo sanitario y la incertidumbre de muerte, donde todos podemos ser un vector de riesgo.

Es importante resaltar que los comportamientos y las sensibilidades confeccionadas en el régimen pandémico también estuvieron orientadas a la pervivencia del sistema y la arquitectura productiva del sistema capitalista. La reconfiguración de los ritmos, las sensibilidades, los metabolismos de los cuerpos y los procesos de subjetivación no siempre están a favor de la preservación de la vida. Estas modulaciones también implican pulsiones microfascistas, la perpetuación de las relaciones de poder y el autocontrol de los individuos a partir de la lógica biocapitalista que mercantiliza todo tipo de vida. La pandemia sacudió nuestros modos de vida y formas de politicidad, las cuales no escaparon del atravesamiento de un poder y un cumulo de racionalidades políticas que resignificaron nuestras formas de vivir, desear, producir y relacionarnos desde la instrumentalización de la vida nuestros cuerpos e imaginarios. 


\section{REFERENCIAS}

Ali, S., y Keil, R. (eds) (2008). Networked Disease: Emerging Infections in the Global City. Wiley-Blackwell.

Baer, A., Merrill S., \& Ida, S. (1997). Medical Anthropology and the World System: A Critical Perspective. Bergin and Garvey.

Bardet, M. (2019). Hacer mundos con gestos, En A. Haudricourt, El Cultivo de los gestos, entre plantas, animales y humanos, (pp. 81-111). Cactus

Borderlands. Annals of the Associations of American Geographers, 101(2), 318-336. https://doi.org/10.1080/o0 045608.2010 .538323

Boyle, P., Norman, P., y Rees, P. (2002). Does migration exaggerate the relationship between deprivation and limiting long-term illness? A Scottish analysis. Social Science and Medicine, 55, 21-31. https://doi. org/10.1016/So277-9536(01)00217-9

Braun, B. (2007). Biopolitics and the molecularization of life. Cultural Geographies, 14(1), 6-28. http://www. jstor.org/stable/44243679

Braun, B. (2008). Thinking the city through SARS: Bodies, topologies, politics. In Sh. Ali and R. Keil (eds.). Networked Disease: Emerging Infections in the Global City, (pp. 250-266). Wiley-Blackwell.

Brown, M. (2006). Sexual Citizenship, Political Obligation and Disease Ecology in Gay Seattle. Political Geography, 25, 874-98. https://doi.org/10.1016/j.polgeo.2006.05.004

Han, B. (2021). No cosas: quiebras del mundo de hoy. Tauro.

Castree, N. (2003). Environmental issues: Relational ontolo-gies and hybrid politics. Progress in Human Geography, 27(2), 203-211. http://dx.doi.org/10.1191/0309132503ph422pr

Castree N. y Nash C. (2006). Posthuman geographies. Social \& Cultural Geography, 7(4), 501-504. https:// doi.org/10.1080/14649360600825620

CEPAL. (04 de agosto de 2020). El rol de los recursos naturales ante la pandemia por el COVID-19 en América Latina y el Caribe. ENFOQUES. https://cutt.ly/2T57hOI

Coburn, D. (2000). Income Inequality, Social Cohesion and the Health Status of Populations: The Role of Neo-Liberalism. Social Science and Medicine, 5, 135-146. https://doi.org/10.1016/S0277-9536(99)004451

Cox, M., Boyle, P.J., Davey, P. y Morris, A. (2007). Does health-selective migration following diagnosis strengthen the relationship between Type 2 diabetes and deprivation? Social Science and Medicine, 65, 32-42. https://pubmed.ncbi.nlm.nih.gov/17490796/

Cummins, S., Curtis, S., Diez-Roux, A.V. y Macintyre, S. (2007). Understanding and representing 'place' in health research: a relational approach. Social Science and Medicine, 65(9), 1825-38. https://doi. org/10.1016/j.socscimed.2007.05.036

Curtis, S. (2004). Health inequalities: geographical perspectives. Sage.

Curtis, S. y Riva M. (2010). Health geographies I: Complexity theory and human health. Progress in Human Geography, 34, 215-223. https://doi.org/10.1177/0309132509336026

Dirección General de Comunicación Social. (2021, enero 31). A la pandemia se suma otro problema. La generación de desperdicios. DGCS https://www.dgcs.unam.mx/boletin/bdboletin/2021_08o.html

Dirección General de Epidemiología. (2021, agosto 5). Semáforo epidemiológico. Gobierno de México. https://datos.covid-19.conacyt.mx/

Deleuze, G. (2015). La subjetivación. Editorial Cactus.

Durand, L. y Sundberg J. (2019). Sobre la ecología política posthumanista. Sociedad y Ambiente, 20, 7-27. https://doi.org/10.31840/sya.voi20.1989

EL CEO. (2021, septiembre 28). ¿Cuántas personas se han vacunado contra covid-19 en México y el mundo? Así va el proceso. El CEO. https://cutt.ly/2TVus2p 
El Economista. (2020, febrero 11). Fenómeno delivery: las entregas de comida se dispararon en 2020. El Economista. https://cutt.ly/yT57cV 5

El Tiempo. (2020, abril 21). Antibacterial y tapabocas, lo más buscado en el mundo del e-Commerce. El Tiempo. https://cutt.ly/FT55fiw

Editorial. (2021, marzo 19). Los consumidores mexicanos a un año de la pandemia. Retailers.mx. https:// cutt.ly/MT6qHII

Emch, M., Feldacker, C., Yunus, M., Streatfi eld, P.K., Thiem, V.D., Canh, D.G. and Ali, M. (2008). Local environmental drivers of cholera in Bangladesh and Vietnam. American Journal of Tropical Medicine and Hygiene, 78, 823-32. https://doi.org/10.4269/ajtmh.2008.78.823

Ennis-McMillan, C. (2001). Suffering from Water: Social Origins of Bodily Distress in a Mexican Community. Medical Anthropology Quarterly, 15(3), 368-390. https://www.jstor.org/stable/649585

Ferrando, F. (2013). Posthumanism, Transhumanism, Antihumanism, Metahumanism, and New Materialisms Differences and Relations. Existenz. An International Journal in Philosophy, Religión, Politics, and the Arts, 8(2), pp. 26-32. https://existenz.us/volumes/Vol.8-2Ferrando.html

Foucault M. (1979). Microfísica del poder. Las Ediciones de La Piqueta.

Foucault, M. (1982). La hermenéutica del sujeto. Fondo de Cultura Económica.

Foucault, M. (1984). Cómo se ejerce el Poder. En H. Dreyfus, P. Rabinow y M. Foucault, Un Parcours Philosophique. Éditions Gallimard.

Foucault, M. (1991). Governmentality. In G. Burchell, C. Gordon, and P. Miller, (eds), The Foucault Effect: Studies in Governmentality, (pp. 87-104). University of Chicago Press.

Foucault, M. (1995). Vigilar y castigar. Siglo XXI.

Foucault, M. (1996). Tecnologías del yo, trad. Mercedes Allende Salazar. Paidós.

Filosofía del Pórtico. (2020). El mito del buen ciudadano. Sobre mecanismos de disciplina y auto- vigilancia. Tropel ediciones.

Gabrielson, T., y Parady, K. (2010). Corporeal citizenship: rethinking green citizenship through the body. Environmental Politics, 19(3), 374-391. https://doi.org/10.1080/09644011003690799

Geronimus, A. (2000). To Mitigate, Resist, or Undo: Addressing Structural Influences on the Health of Urban Populations. American Journal of Public Health, 9o(6), 867-872. https://doi.org/10.2105/AJPH.90.6.867

Gonzalez, S. (2021, mayo 5). Gastos Médicos. Mexicanos buscan seguros tras la pandemia. Reporte Indigo. https://ng.cl/7xi62

Greenhough, B. (2012). Where species meet and mingle: endemic human-virus relations, embodied communication and more than-human agency at the Common Cold Unit 1946-90. Cultural geographies, 19(3), 281-301. https://doi.org/10.1177/1474474011422029

Guattari F. (2008). La ciudad subjetiva y post-mediática/ La polis reinventada, Trad. De Ernesto Hernández y Carlos Enrique Restrepo. Fundación Comunidad.

Guattari, F. (2017). Las tres ecologías. Pre-textos.

Guthman, J., y Mansfield, B. (2012). The implications of environmental epigenetics: A new direction for geographic inquiry on health, space, and nature-society relations. Progress in Human Geography, 37(4), 486-504, https://doi.org/10.1177\%2F0309132512463258

Haraway, D. (2003). The companion species manifesto: Dogs, people, and significant otherness. Prickly Paradigm. Haraway, D. (2008). When Species Meet. Minneapolis. University of Minnesota Press.

Harper, J. (2004). Breathless in Houston: A political ecology of health approach to understanding environmental health concerns. Medical Anthropology: Cross-Cultural Studies in Health and Illness, 23, 295-326. https://doi.org/10.1080/01459740490513521 
Hanchette, C. (2008). The political ecology of lead poisoning in eastern North Carolina. Health and Place, 14, 209-16. https://doi.org/10.1016/j.healthplace.2007.06.003

Haesbaert, R. (2011). El mito de la desterritorialización. Del fin de los territorios a la Multiterritorialidad. Siglo $\mathrm{XXI}$.

Hernández Cruz, D., y Pelayo Pérez, M. (2020). Necropolítica del despojo, una ofensiva contra el pueblo. URVIO. Revista Latinoamericana De Estudios De Seguridad, (28), 118-133. https://doi.org/10.17141/ urvio.28.2020.4402

Hobson, K. (2007). Political Animals? On Animals as Subjects in an Enlarged Political Geography. Political Geography, 26(3), 250 67. http://dx.doi.org/10.1016/j.polgeo.2006.10.010

Leff Zimmerman, E. (1998) Saber Ambiental: Sustentabilidad, Racionalidad, Complejidad, Poder. Siglo XXI/ UNAM/PNUMA.

Leff Zimmerman, E. (2014). La apuesta por la vida. Imaginación sociológica e imaginarios sociales en territorios ambientales del sur. Siglo XXI.

Mayer, J. (2000). Geography, ecology and emerging infectious diseases. Social Science and Medicine, 50, 937-52. https://doi.org/10.1016/So277-9536(99)00346-9

Mendoza, V. (2021, marzo 4). 30\% de quienes han muerto por Covid-19 tenían seguro de vida. FORBES. https://ng.cl/azflo

Miranda, C. (2012). Biopolítica en el Mundo Contemporáneo. Revista Sociedad y Equidad, (3), 211-221. http:// doi.org/10.5354/0718-9990.2012.18097

Nair Calvo, D. (2002). Organización política auto-referenciada en sectores populares. El caso de la Federación de Tierra Vivienda y Hábitat. CLACSO. https://cutt.ly/GYlzegl

Nair Calvo, D. (2004). Politicidad, reflexividad y auto-referencia organizada ¿Estamos hablando de política? [Congreso] VI Jornadas de Sociología. Facultad de Ciencias Sociales, Universidad de Buenos Aires.

Organización Mundial de la Salud (2020, octubre 28). Enfermedad por el coronavirus (COVID-19): Vacunas. OMS. https://cutt.ly/DYl3oAW

Ortner, S. (2005). Geertz, subjetividad y conciencia posmoderna. Etnografías contemporáneas, 1(1).

Pelayo Pérez, M. (2020). Reconfiguración de modos de vida, mecanismos de respuesta local y procesos emergentes de gobernanza ambiental de comunidades aledañas a presas hidroeléctricas en el Río Santiago, Nayarit, México [tesis de doctorado, Universidad Nacional Autónoma de México]. Dirección General de Bibliotecas. Departamento de Tesis http://132.248.9.195/ptd2020/marzo/0801687/Index. html

Procter, K.L., Clarke, G.P., Ransley, J.K. y Cade, J. (2008). Micro-level analysis of childhood obesity, diet, physical activity, residential socioeconomic and social capital variables: where are the obesogenic environments in Leeds? Area, 40(3) 23-40. https://www.jstor.org/stable/40346136

Rocheleau, D., y Roth, R. (2007). Rooted Networks, Relational Webs and Powers of Connection: Rethinking Human and Political Ecologies. Geoforum, 38, 433-437. https://link.springer.com/ chapter/10.1007/978-1-137-38273-3_15

Rodríguez, M. (2010). Politicidad, acción política y marco histórico interpretativo: dimensiones políticas en las prácticas de los mensajeros en moto del Ámbito Metropolitano de Buenos Aires (AMBA). Temas y debates, 19.

Sánchez, A., y Valdés, M. (2020). Comportamiento informacional, infodemia y desinformación durante la pandemia de COVID-19. Anales de la Academia de Cuba, 10(2), e882. http://revistaccuba.sld.cu/index. php/revacc/article/view/882

Sibilia, P. (2008). La intimidad como espectáculo. Fondo de Cultura Económica. 
Sundberg, J. (2011). Diabolic Caminos in the Desert and Cat Fights on the R.o: A Posthumanist Political Ecology of Boundary Enforcement in the United States-Mexico. Annals of the Association of American Geographers, 101(2), 318-336. https://doi.org/10.1080/00045608.2010.538323

Spinoza, B. (1987). Ética, edición por Vidal Peña. Alianza Editorial.

Statista (2021a, octubre 18). Número de personas fallecidas a consecuencia del coronavirus a nivel mundial a fecha de 10 de octubre de 2021, por continente. Statista. https://cutt.ly/FT6wh20

Statista (2021b, octubre 14). Número de personas fallecidas a causa del coronavirus en el mundo a fecha de 8 de octubre de 2021, por país. Statista. https://cutt.ly/rT6wchM

Sze, J. (2006). Boundaries and border wars: DES, technology, and environmental justice. The American Studies Association, 58(3), 791-814. https://www.jstor.org/stable/40068393

Turshen, M. (1977). The political ecology of disease. The Review of Radical Political Economics, 9(1), 45-60. https://doi.org/10.1177\%2F048661347700900104

Toche, N. (2021, febrero 15). La pandemia cambió los hábitos de consumo de agua: el grave problema que viene. El Economista. https://cutt.ly/xT6wDru

Van Loon, J. (2005). Epidemic Space. Critical Public Health, 15(1), 39-52. http://dx.doi. org/10.1080/09581590500048374

\section{AUTORA}

Mariana Betzabeth Pelayo Pérez. Doctora en ciencias de la Sostenibilidad por la Universidad Nacional Autónoma de México y actualmente docente- investigadora de la Unidad Académica de Ciencias Sociales de la Universidad Autónoma de Nayarit. 